\title{
Sequential Targeting of Xylose and Glucose Conversion in Fed-Batch Simultaneous Saccharification and Co-fermentation of Steam-Pretreated Wheat Straw for Improved Xylose Conversion to Ethanol
}

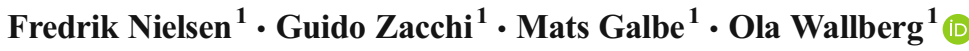 \\ Published online: 11 May 2017 \\ (C) The Author(s) 2017. This article is an open access publication
}

\begin{abstract}
Efficient conversion of both glucose and xylose in lignocellulosic biomass is necessary to make secondgeneration bioethanol from agricultural residues competitive with first-generation bioethanol and gasoline. Simultaneous saccharification and co-fermentation (SSCF) is a promising strategy for obtaining high ethanol yields. However, with this method, the xylose-fermenting capacity and viability of yeast tend to decline over time and restrict the xylose utilization. In this study, we examined the ethanol production from steampretreated wheat straw using an established SSCF strategy with substrate and enzyme feeding that was previously applied to steam-pretreated corn cobs. Based on our findings, we propose an alternative SSCF strategy to sustain the xylose-fermenting capacity and improve the ethanol yield. The xylose-rich hydrolyzate liquor was separated from the glucose-rich solids, and phases were co-fermented sequentially. By prefermentation of the hydrolyzate liquor followed fedbatch SSCF, xylose, and glucose conversion could be targeted in succession. Because the xylose-fermenting capacity declines over time, while glucose is still converted, it was advantageous to target xylose conversion upfront. With our strategy, an overall ethanol yield of $84 \%$ of the theoretical
\end{abstract}

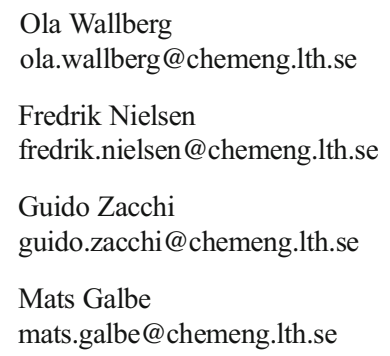

1 Department of Chemical Engineering, Lund University, P.O. Box 124, 22100 Lund, Sweden maximum based on both xylose and glucose was reached for a slurry with higher inhibitor concentrations, versus $92 \%$ for a slurry with lower inhibitor concentrations. Xylose utilization exceeded $90 \%$ after SSCF for both slurries. Sequential targeting of xylose and glucose conversion sustained xylose fermentation and improved xylose utilization and ethanol yield compared with fed-batch SSCF of whole slurry.

Keywords Co-fermentation · Prefermentation . Saccharomyces cerevisiae $\cdot$ Lignocellulose $\cdot$ Xylose $\cdot$ Ethanol

\section{Introduction}

The production of fuel ethanol from lignocellulosic raw materials is associated with technological and economic hurdles that must be addressed to make lignocellulosic fuel ethanol competitive with first-generation fuel ethanol and gasoline. Raw material costs constitute a substantial part of the total production cost [1], necessitating efficient use of the raw material to improve the process economics. High ethanol yield and final ethanol concentration are key factors for improved profitability [2], and the major technological challenges to achieve them are linked to the biology and chemistry of the processing steps in using the raw materials efficiently. Accessing and converting the high xylose content in hardwood and agricultural feedstocks to ethanol are central for improving the process ethanol yield and economics [3, 4].

The overall performance of the fermentation step depends largely on the tolerance of the fermenting microorganism to inhibitors and its ability to efficiently convert a variety of substrates to ethanol. Saccharomyces cerevisiae has high ethanol productivity and tolerance to ethanol and inhibitory compounds in lignocellulosic hydrolyzates under anaerobic conditions. However, it is largely unable to utilize xylose as 
substrate [5]. Xylose-fermenting capabilities have been achieved in $S$. cerevisiae by introduction of a two-step pathway catalyzed by xylose reductase (XR) and xylitol dehydrogenase $(\mathrm{XDH})$, as well as a one-step pathway catalyzed xylose isomerase (XI) [6-8]. The XR/XDH pathway encompasses the reduction of xylose to xylitol by the NAD(P)H-preferring $\mathrm{XR}$ and oxidation of xylitol to xylulose by the NADH-linked $\mathrm{XDH}[6,7]$. In contrast, the co-factor-independent XI catalyzes the direct isomerization of xylose to xylulose [8]. Ethanol productivity and yield during fermentation have been further improved by overexpression of endogenous xylulokinase (XK) [9] and engineering of the co-factor specificity of XR $[10,11]$. To attenuate the effect of inhibitors and improve co-fermentation efficiency, strategies that improve the natural tolerance of the microorganism have been developed. Improved tolerance to inhibitors and ability to convert xylose have been achieved by e.g., evolutionary engineering $[12,13]$ and short-term adaptation during propagation [14]. However, xylose is still generally fermented by $S$. cerevisiae to ethanol at lower rates [15] and lower yields than glucose $[15,16]$. This has been attributed to capacity limitations in the pentose phosphate shunt [9] and mismatched co-factor dependency during xylose catabolism in engineered XR/XDHstrains [17]. The co-factor imbalance between NAD(P)H-consuming XR and NADH-producing XDH reactions effects the production of xylitol $[18,19]$.

Limited uptake of xylose by $S$. cerevisiae entails another constraint on the conversion efficiency. Xylose is assimilated by nonspecific hexose transporters [20], and because their affinity for glucose is many-fold higher than for xylose [17], excessive amounts of glucose competitively inhibit the transporters and prevent efficient uptake of xylose. However, coconsumption of glucose and xylose has been shown to increase the xylose uptake rate and reduce xylitol excretion, compared with xylose metabolism alone [21]. Thus, low, but non-zero, concentration of glucose enhances xylose metabolism. The effect has been attributed to improved co-factor generation [22] and the induction of genes for transporter systems [22] and glycolytic enzymes [23].

The benefits of low glucose concentrations for improved xylose conversion renders simultaneous saccharification and co-fermentation (SSCF) an attractive process configuration for the co-fermentation of glucose and xylose. The continuous release of glucose by enzymatic hydrolysis helps maintain low glucose concentrations, which kinetically favor xylose utilization in recombinant $S$. cerevisiae strains [21]. Typically, ethanol productivity [24] and yield are higher in SSCF than with separate hydrolysis and co-fermentation [25, 26]. Ethanol yields in SSCF have been improved with modifications to the co-fermentation strategy, such as fed-batch strategies [27], enzyme feeding [28], and prefermentation [29] and combinations thereof [30-32]. These modifications were introduced to keep glucose concentrations in the bioreactor low.
Prefermentation depletes glucose in the liquid fraction, and substrate and enzyme feeding maintain low glucose concentrations during SSCF, which favors xylose uptake and conversion. However, declining xylose-fermenting capacity $[30,31]$ and exhaustion of the fermenting microorganism [33] have been observed on repeat addition of substrates that contain inhibitors, restricting xylose utilization and, ultimately, limiting the ethanol yield.

Combining prefermentation, feeding of cellulolytic enzymes, and fed-batch SSCF have been established as a feasible approach for obtaining high ethanol yields for cofermentation of biomass-derived glucose and xylose [30, 31]. In this study, we revisited the fed-batch SSCF strategy that was proposed by Koppram et al. [31], which was used for co-fermentation of glucose and xylose from steam-pretreated corncobs. We applied this method to steam-pretreated wheat straw and made modifications to overcome the observed limitations [30, 31]. Pentose-rich hydrolyzate liquor was separated from hexose-rich solids after pretreatment, and the phases were fermented sequentially. By prefermentation of the hydrolyzate liquor followed by fed-batch SSCF, we could target xylose and glucose conversion in succession, thus, creating opportunities for sustaining the xylose-fermenting capacity and improving xylose conversion.

\section{Materials and Methods}

\section{Microorganism}

Fermentation was performed with the noncommercial xylosefermenting $S$. cerevisiae strain KE6-12 (Taurus Energy AB), which harbors genes from Scheffersomyces stipitis (formerly Pichia stipitis) that encode for $\mathrm{XR}$ and $\mathrm{XDH}$ and overexpresses endogenous XK. The strain was developed by evolutionary engineering [34] of the industrial strain S. cerevisiae TMB3400 [35] to improve its tolerance to inhibitors and xylose conversion capacity. Stock culture aliquots contained a mass fraction of $20 \%$ glycerol in water and were stored at $-80^{\circ} \mathrm{C}$.

\section{Raw Material and Preprocessing}

Two batches of wheat straw that were pretreated by diluteacid-catalyzed steam pretreatment were procured from SEKAB E-Technology AB (Örnsköldsvik, Sweden). The slurries were denoted mild and severe, respectively, based on the relative inhibitor concentrations. The mild slurry was prepared by impregnation of the wheat straw with dilute $\mathrm{H}_{2} \mathrm{SO}_{4}$, $\mathrm{pH} 1.7$, and steam pretreatment at $187^{\circ} \mathrm{C}$ for $8 \mathrm{~min}$. The pretreated material had a water-insoluble solids (WIS) content of $11.1 \mathrm{wt} \%$. The severe slurry was impregnated with dilute $\mathrm{H}_{2} \mathrm{SO}_{4}, \mathrm{pH} 2.4$, and steam-pretreated at $190{ }^{\circ} \mathrm{C}$ for $15 \mathrm{~min}$. 
The pretreated material had a WIS content of $13.9 \mathrm{wt} \%$. The compositions of the slurries are summarized in Table 1. The $\mathrm{pH}$ of the slurries was adjusted to 5 with $12.5 \mathrm{M} \mathrm{NaOH}$.

The hydrolyzate liquor in slurries that were intended for fed-batch SSCF with prefermentation of the hydrolyzate liquor was separated from the solids by filtration using a hydraulic press (HP5M, Fischer Maschinenfabrik). The retained unwashed solid fractions of the severe and mild slurries contained 34 and $38 \mathrm{wt} \%$ WIS, respectively, after filtration.

\section{Cultivation of Yeast}

The precultures were cultivated in $250-\mathrm{mL}$ shake flasks with $150 \mathrm{~mL}$ of sterile minimal medium, containing $20 \mathrm{~g} \mathrm{~L}^{-1}$ glucose, $20 \mathrm{~g} \mathrm{~L}^{-1}$ xylose, $7.5 \mathrm{~g} \mathrm{~L}^{-1}\left(\mathrm{NH}_{4}\right)_{2} \mathrm{SO}_{4}, 3.75 \mathrm{~g} \mathrm{~L}^{-1}$ $\mathrm{KH}_{2} \mathrm{PO}_{4}$, and $0.75 \mathrm{~g} \mathrm{~L}^{-1} \mathrm{MgSO}_{4}$, that was supplemented with $1 \mathrm{~mL} \mathrm{~L}^{-1}$ vitamin solution and $10 \mathrm{~mL} \mathrm{~L}^{-1}$ trace element solution, per Taherzadeh et al. [36]. The $\mathrm{pH}$ of the medium was adjusted to 5.5 with $5 \mathrm{M} \mathrm{NaOH}$. The precultures were inoculated with $300 \mu \mathrm{L}$ of stock cell aliquot and incubated at $30^{\circ} \mathrm{C}$ on an orbital shaker (Lab-Therm, Kühner) at $180 \mathrm{rpm}$ for $24 \mathrm{~h}$.

The cultivations were performed in a sterilized 2-L Labfors bioreactor (Infors AG) that was equipped with two 6-blade Rushton turbines. The reactor diameter:impeller diameter ratio was 3 , and the reactor height:diameter ratio was 1.7 . The yeast was propagated by aerobic batch cultivation on molasses, followed by aerobic fed-batch cultivation on wheat straw hydrolyzate liquor and molasses. The batch cultivation was performed with $50 \mathrm{~g} \mathrm{~L}^{-1}$ molasses solution that was supplemented with $23.5 \mathrm{~g} \mathrm{~L}^{-1}\left(\mathrm{NH}_{4}\right)_{2} \mathrm{SO}_{4}, 3 \mathrm{~g} \mathrm{~L}^{-1} \mathrm{KH}_{2} \mathrm{PO}_{4}$, $2.25 \mathrm{~g} \mathrm{~L}^{-1} \mathrm{MgSO}_{4} \cdot 7 \mathrm{H}_{2} \mathrm{O}, 33 \mu \mathrm{g} \mathrm{L}^{-1}$ biotin, and $120 \mathrm{ppm}$ Vitahop (BetaTec). The molasses (Nordic Sugar A/S) contained $40 \mathrm{wt} \%$ of fermentable sugars (sucrose, fructose, and glucose), lactic acid $\left(0.034 \mathrm{~g} \mathrm{~g}^{-1}\right)$, and acetic acid $\left(0.008 \mathrm{~g} \mathrm{~g}^{-1}\right)$. The cultivation was initiated by inoculation with the preculture. The batch culture had a working volume of $0.5 \mathrm{~L}$, a constant aeration rate of $1 \mathrm{vvm}$, and an agitation rate of $700 \mathrm{rpm}$. The $\mathrm{pH}$ was maintained automatically at 5.2 with sterile $2.5 \mathrm{M} \mathrm{NaOH}$ solution. The batch phase was concluded when all sugars were consumed, as indicated by the evolution of carbon dioxide and oxygen in the bioreactor gas effluent.

The fed-batch phase was initiated after fermentable sugars were depleted in the batch phase. The feed solution comprised diluted hydrolyzate liquor from the slurry used in the subsequent SSCF and was supplemented with $150 \mathrm{~g} \mathrm{~L}^{-1}$ molasses. The hydrolyzate liquor in the feed solution effected inhibitor concentrations in the final working volume that corresponded to the concentrations in a broth with a WIS load of $7.5 \mathrm{wt} \%$. The purpose of including the hydrolyzate liquor in the fedbatch phase was to improve the tolerance of the yeast by shortterm adaptation of the cultivated yeast to the environmental conditions in the fermentation experiments, per Nielsen et al.
Table 1 Pretreatment conditions and composition of steam-pretreated wheat straw materials

\begin{tabular}{|c|c|c|}
\hline & Mild & Severe \\
\hline \multicolumn{3}{|c|}{ Steam pretreatment conditions } \\
\hline Temperature $\left({ }^{\circ} \mathrm{C}\right)$ & 187 & 190 \\
\hline Hold-up time (min) & 8 & 15 \\
\hline $\mathrm{pH}(-)$ & 1.7 & 2.4 \\
\hline WIS content (wt \%) & 11.1 & 13.9 \\
\hline \multicolumn{3}{|c|}{ Composition of WIS (wt\%) } \\
\hline Glucan & 50.7 & 51.4 \\
\hline Xylan & 1.0 & 1.7 \\
\hline Galactan & BDL & BDL \\
\hline Arabinan & 0.1 & 0.1 \\
\hline Mannan & 0.1 & 0.1 \\
\hline Acid-soluble lignin & 0.6 & 0.7 \\
\hline Acid-insoluble lignin & 29.8 & 33.8 \\
\hline Ash & 10.2 & 6.9 \\
\hline \multicolumn{3}{|c|}{ Content in hydrolyzate liquor $\left(\mathrm{g} \mathrm{L}^{-1}\right)$} \\
\hline Glucose $^{\mathrm{a}}$ & 8.7 & 14.5 \\
\hline Xylose $^{\mathrm{a}}$ & 35.4 & 32.6 \\
\hline Galactose & 0.9 & $\mathrm{BDL}$ \\
\hline Arabinose & 1.8 & 3.5 \\
\hline Mannose & 0.7 & 1.8 \\
\hline Formic acid & 0.8 & 1.6 \\
\hline Levulinic acid & 0.5 & BDL \\
\hline Acetic acid & 5.6 & 8.5 \\
\hline HMF & 0.3 & 1.3 \\
\hline Furfural & 3.7 & 7.7 \\
\hline
\end{tabular}

$B D L$ below detection limit

${ }^{\text {a }}$ Both monomeric and oligomeric forms are included

[14]. The feed solution was pulse-fed to the bioreactor at a constant rate for $20 \mathrm{~h}$ to a final working volume of $1.5 \mathrm{~L}$. The reactor was aerated by sparging at a constant rate of $1 \mathrm{vvm}$, based on the final volume, and the $\mathrm{pH}$ was maintained at 5.2 automatically with sterile $2.5 \mathrm{M} \mathrm{NaOH}$ solution.

The propagated yeast was harvested by centrifugation ( $3800 \times g, 10 \mathrm{~min}$ ) and washed with $9 \mathrm{~g} \mathrm{~L}^{-1}$ sterile $\mathrm{NaCl}$ solution. The cell pellets were resuspended in sterile $9 \mathrm{~g} \mathrm{~L}^{-1} \mathrm{NaCl}$ solution to yield an inoculum with a cell dry matter concentration of $120 \mathrm{~g} \mathrm{~L}^{-1}$.

\section{Simultaneous Saccharification and Co-fermentation}

\section{Fed-Batch SSCF of Whole Slurry}

Fed-batch SSCF of whole slurry (Fig. 1a) was performed with severe wheat straw slurry in a sterilized 30-L NLF22 bioreactor (Bioengineering $\mathrm{AG}$ ) that was equipped with two pitched 6-blade turbines. The reactor diameter:impeller diameter ratio was 1.7 , and the reactor height:diameter ratio was 2.75 . 
Fig. 1 Schematics of SSCF strategies. a Fed-batch SSCF with whole slurry and $\mathbf{b}$ fed-batch SSCF with prefermentation a

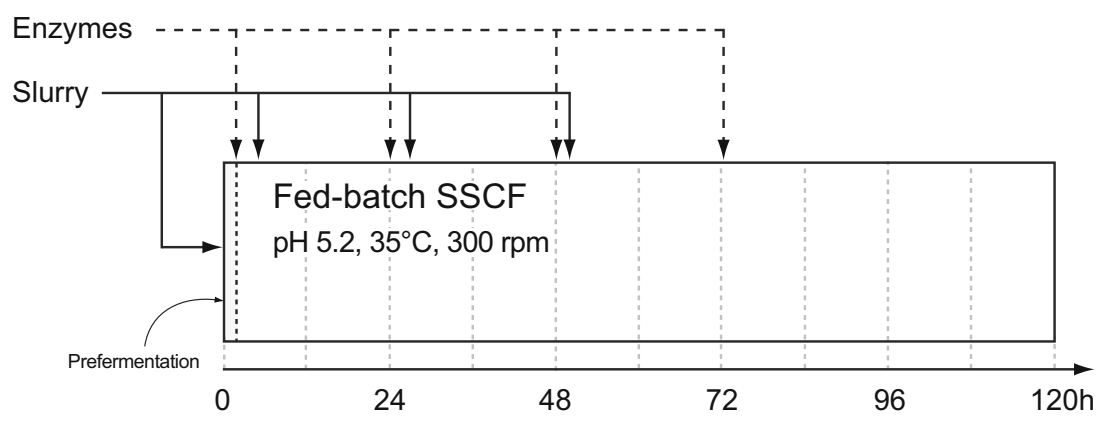

b

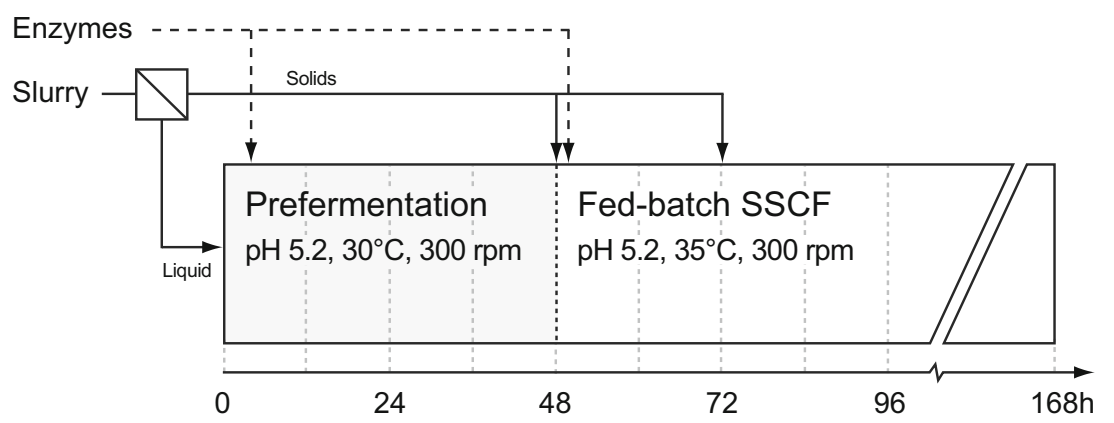

Fermentation was performed with a final working weight of $15 \mathrm{~kg}$ and a total WIS load of $10 \mathrm{wt} \%$. The strategy was a modified version of the 30-L scale fed-batch SSCF of steampretreated corncobs that was reported by Koppram et al. [31]. The fed-batch SSCF was carried out at $35^{\circ} \mathrm{C}$ with $7 \mathrm{wt} \%$ of the total amount of slurry at the outset, inoculated with $5 \mathrm{~g} \mathrm{~L}^{-1}$ of yeast dry matter, and supplemented with $0.5 \mathrm{~g} \mathrm{~L}^{-1}$ $\left(\mathrm{NH}_{4}\right)_{2} \mathrm{HPO}_{4}, 0.125 \mathrm{~mL} \mathrm{~L}^{-1}$ Vitahop (BetaTec), and $0.4 \mathrm{~mL} \mathrm{~L}^{-1}$ Antifoam RD Emulsion (Dow Corning), all based on the final volume. Prefermentation was performed for $2 \mathrm{~h}$ to deplete glucose in the liquid fraction of the initial amount of slurry. The bioreactor was then fed with three additions of slurry — each $31 \mathrm{wt} \%$ of the total amount of slurry - after 5, 27, and $49 \mathrm{~h}$. Cellic CTec2 enzyme preparation (Novozymes $\mathrm{A} / \mathrm{S}$ ), corresponding to a cellulolytic activity of $2.5 \mathrm{FPU} \mathrm{g}^{-1}$ WIS, was added $2 \mathrm{~h}$ after initial substrate addition to hydrolyze lignocellulosic solids and spiked with an additional 2.5 FPU g ${ }^{-1}$ at 24,48 , and $72 \mathrm{~h}$, yielding a total enzyme load of $10 \mathrm{FPU} \mathrm{g}^{-1}$ WIS, based on total ingoing WIS. The agitation rate was set to $300 \mathrm{rpm}$ throughout the fermentation, and $\mathrm{pH}$ was maintained at 5.2 by automatic addition of sterile $2.5 \mathrm{M}$ $\mathrm{NaOH}$ solution.

\section{Prefermentation Followed by Fed-Batch SSCF}

Prefermentation of hydrolyzate liquor followed by fed-batch SSCF (Fig. 1b) was performed with mild and severe wheat straw slurry in sterilized 2-L Labfors bioreactors (Infors AG) that were equipped with an anchor impeller and a pitched 6blade turbine. The reactor diameter:impeller diameter ratio was 1.5 for the anchor impeller and 1.7 for the pitched 6blade turbine, and the reactor height:diameter ratio was 1.7. Co-fermentation was performed with a final working weight of $1.5 \mathrm{~kg}$ and a total WIS load of $10 \mathrm{wt} \%$.

The fermentation was conducted sequentially by batch prefermentation of the separated hydrolyzate liquor followed by fed-batch SSCF of the unwashed solids (Fig. 1b). The separated hydrolyzate liquor was supplemented at the outset with $0.5 \mathrm{~g} \mathrm{~L}^{-1}\left(\mathrm{NH}_{4}\right)_{2} \mathrm{HPO}_{4}, 0.125 \mathrm{~mL} \mathrm{~L}^{-1}$ Vitahop (BetaTec), and $0.4 \mathrm{~mL} \mathrm{~L}^{-1}$ Antifoam RD Emulsion (Dow Corning), all based on the final volume. The hydrolyzate liquor was inoculated with $5 \mathrm{~g} \mathrm{~L}^{-1}$ of yeast dry matter, based on the final volume, and prefermented at $30{ }^{\circ} \mathrm{C}$ for $48 \mathrm{~h}$. An enzyme load of 2 FPU g ${ }^{-1}$ WIS of Cellic CTec2, based on the total ingoing WIS, was added after $4 \mathrm{~h}$ to hydrolyze oligosaccharides in the hydrolyzate liquor.

After prefermentation-i.e., after $48 \mathrm{~h}$-half of the unwashed solids was added to the prefermented hydrolyzate liquor. In conjunction was Cellic CTec2 added, yielding a total cellulolytic activity of $10 \mathrm{FPU} \mathrm{g} \mathrm{WIS}^{-1}$ based on the total ingoing WIS. The temperature was increased to $35^{\circ} \mathrm{C}$ to increase enzymatic activity. The remaining unwashed solids were added after $72 \mathrm{~h}$. Agitation was maintained at $300 \mathrm{rpm}$ throughout the fermentation, and $\mathrm{pH}$ was maintained at 5.2 by 
automatic addition of sterile $2.5 \mathrm{M} \mathrm{NaOH}$ solution. The fermentation was terminated after $168 \mathrm{~h}$.

\section{Analytical Procedures}

Extracellular metabolites, inhibitors, and sugars were quantified by high-performance liquid chromatography (HPLC) on a Shimadzu HPLC system that was equipped with an RID10A refractive index detector (Shimadzu). Samples for carbohydrate analysis were $\mathrm{pH}$-adjusted to 5, when needed, with $\mathrm{CaCO}_{3}$ and centrifuged in $10-\mathrm{mL}$ tubes $(960 \times \mathrm{g}, 5 \mathrm{~min})$. All samples were centrifuged $(16,000 \times \mathrm{g}, 3 \mathrm{~min})$, and the supernatants were filtered through $0.20-\mu \mathrm{m}$ syringe filters (GVS Filter Technology). The filtered samples were stored at $-20{ }^{\circ} \mathrm{C}$ until analysis. Extracellular metabolites, organic acids, and degradation products in the samples were analyzed by isocratic ion-exchange chromatography on an Aminex HPX$87 \mathrm{H}$ column (Bio-Rad Laboratories) at $50{ }^{\circ} \mathrm{C}$. The eluent was $5 \mathrm{mM} \mathrm{H}_{2} \mathrm{SO}_{4}$, applied at a flow rate of $0.5 \mathrm{~mL} \mathrm{~min}^{-1}$. Sugars and xylitol in the samples were quantified by isocratic ionexchange chromatography on an Aminex HPX-87P column (Bio-Rad Laboratories) at $85^{\circ} \mathrm{C}$. Deionized water was used as the eluent at a flow rate of $0.5 \mathrm{~mL} \mathrm{~min}^{-1}$.

The dry matter content of solids and water-insoluble solids were measured per Sluiter et al. [37] and Sluiter et al. [38], respectively. Solubilized carbohydrates and pretreatment degradation products in the hydrolyzate liquor were quantified per Sluiter et al. [39]. Further, structural carbohydrates, lignin, and ash content in the water-insoluble fraction of the wheat straw slurries before and after fermentation were measured per Sluiter et al. [40].

\section{Calculation of Yields}

Ethanol yields were calculated at two levels: an overall ethanol yield and a metabolic ethanol yield. The overall yield was based on total supplied glucose and xylose-i.e., the sum of glucose and xylose in the slurries after pretreatment, including monomers, oligomers, and polymers. The metabolic yield was based on consumed glucose and xylose, and calculated per Palmqvist and Lidén [41]. The consumed glucose and xylose was defined as the difference between total ingoing glucose and xylose in the slurry and residual solubilized sugars, glucan, and xylan in the fermentation broth and solid SSCF residues after fermentation. Note: polysaccharides in the cell wall of the yeast may affect glucan measurements in the SSCF residues [42], but nevertheless the method provides an approximation of glucan and xylan content in the lignocellulosic residues. The mass of glucose and xylose that were available in the form of polymers in the WIS was corrected by the factors 1.111 and 1.136, respectively, to account for the hydration during the hydrolytic cleaving. The percentage of maximum theoretical ethanol yield was based on a theoretical stoichiometric yield of $0.51 \mathrm{~g} \mathrm{~g}^{-1}$ for glucose and xylose.

\section{Results and Discussion}

In this study, a fed-batch SSCF strategy that was developed for co-fermentation of steam-pretreated corncobs was applied to the co-fermentation of steam-pretreated wheat straw. Based on the findings for the fed-batch SSCF method, an alternative strategy was proposed-sequential co-fermentation with prefermentation of the hydrolyzate liquor followed by fedbatch SSCF - to improve the overall ethanol yield by increasing the consumption and conversion of xylose. Our cofermentation results were compared with those for fed-batch SSCF with steam-pretreated corncobs on a 30-L scale with S. cerevisiae KE6-12 [31] and steam-pretreated wheat straw on a lab-scale with the progenitor strain $S$. cerevisiae TMB 3400 [30]. The conditions and results obtained in this study and in referenced studies are summarized in Tables 2 and 3, respectively. Further, the performance of prefermentation followed by fed-batch SSCF was compared with that of prefermentation of the hydrolyzate liquor coupled to SHCF [33], which was performed using the same pretreated wheat straw.

\section{Fed-Batch SSCF of Whole Slurry}

The fed-batch SSCF strategy for whole slurry (Fig. 1a) that was derived from Koppram et al. [31] was unsuitable for cofermentation of severe wheat straw slurry - the fermentation performance declined over time and negligible xylose conversion and accumulation of glucose occurred in the later stages of the SSCF (Fig. 2). Although xylose utilization was higher than reported by Koppram et al. [31] - 65 versus 55\% - the overall ethanol yield was $56 \%$ of the theoretical maximum (Table 3), lower than the $69 \%$ in Koppram et al. [31].

The lower ethanol yield was likely connected to differences between pretreated raw materials (Table 2). Repeat addition of slurry, and thus inhibitors, seemingly exhausted the fermenting microorganism, as observed for the strain in Nielsen et al. [33], and xylose-fermenting capacity declined with each addition of severe slurry during the fed-batch phase (Fig. 2). The declining viability and xylose consumption prevented high overall ethanol yields from being obtained with this SSCF strategy.

Declining xylose-fermenting capacity throughout the cofermentation was also noted by Koppram et al. [31] and during co-fermentation of steam-pretreated wheat straw with the progenitor strain S. cerevisiae TMB3400 [30], likely due to decreasing viability of the pitched yeast. The inhibitors, in combination with the synergism between the ethanol concentration and fermentation temperature that was needed to 
Table 2 Summary of experimental conditions

Experimental conditions

Inhibitor concentrations

\begin{tabular}{|c|c|c|c|c|c|c|c|c|}
\hline Strain & Substrate & $\begin{array}{l}\text { Duration } \\
\mathrm{h}\end{array}$ & $\begin{array}{l}\text { WIS } \\
\text { wt } \%\end{array}$ & $\begin{array}{l}\text { Yeast load } \\
\text { g DM L }^{-1}\end{array}$ & $\begin{array}{l}\text { Enzyme load } \\
\text { FPU g }{ }^{-1} \text { WIS }\end{array}$ & $\begin{array}{l}\text { Acetic acid } \\
\mathrm{g} \mathrm{L}^{-1}\end{array}$ & $\begin{array}{l}\mathrm{HMF} \\
\mathrm{g} \mathrm{L}^{-1}\end{array}$ & $\begin{array}{l}\text { Furfural } \\
\mathrm{g} \mathrm{L}^{-1}\end{array}$ \\
\hline
\end{tabular}

\begin{tabular}{|c|c|c|c|c|c|c|c|c|c|}
\hline \multicolumn{10}{|l|}{ Referenced studies } \\
\hline Fed-batch SSCF [30] & TMB3400 & STEX-WS & 100 & 11 & 4 & 20 & $2.5-3.4$ & $0.2-0.5$ & $3.1-4.9$ \\
\hline Fed-batch SSCF [31] & KE6-12 & STEX-CC & 168 & 10 & 5 & 15 & 8.3 & 1.9 & 4.0 \\
\hline Fed-batch SHCF with prefermentation [33] & KE6-12 & $\begin{array}{l}\text { STEX-WS } \\
\text { Severe }\end{array}$ & 144 & 10 & 5 & 10 & 8.5 & 1.3 & 7.7 \\
\hline Fed-batch SHCF with prefermentation [33] & KE6-12 & $\begin{array}{l}\text { STEX-WS } \\
\text { Mild }\end{array}$ & 144 & 10 & 5 & 10 & 5.6 & 0.3 & 3.7 \\
\hline \multicolumn{10}{|l|}{ This study } \\
\hline $\begin{array}{l}\text { Fed-batch SSCF ("Fed-Batch SSCF } \\
\text { of Whole Slurry" section) }\end{array}$ & KE6-12 & $\begin{array}{l}\text { STEX-WS } \\
\text { Severe }\end{array}$ & 120 & 10 & 5 & 10 & 8.5 & 1.3 & 7.7 \\
\hline $\begin{array}{l}\text { Fed-batch SSCF with prefermentation } \\
\text { ("Prefermentation Followed by Fed-Batch } \\
\text { SSCF" section) }\end{array}$ & KE6-12 & $\begin{array}{l}\text { STEX-WS } \\
\text { Severe }\end{array}$ & 144 & 10 & 5 & 10 & 8.5 & 1.3 & 7.7 \\
\hline $\begin{array}{l}\text { Fed-batch SSCF with prefermentation } \\
\text { ("Prefermentation Followed by Fed-Batch } \\
\text { SSCF" section) }\end{array}$ & KE6-12 & $\begin{array}{l}\text { STEX-WS } \\
\text { Mild }\end{array}$ & 168 & 10 & 5 & 10 & 5.6 & 0.3 & 3.7 \\
\hline
\end{tabular}

STEX acid-catalyzed steam explosion, $C C$ corn cobs, WS wheat straw

facilitate the enzymatic hydrolysis during SSCF [43], likely adversely affected the viability. In our fed-batch SSCF of whole slurry, the decrease in viability caused glucose to accumulate in the bioreactor after $72 \mathrm{~h}$ of co-fermentation (Fig. 2). However, Olofsson et al. [30] showed that lower viability was not the sole reason for the decline in xylose-fermenting capacity by pitching fresh yeast in the late stages of the SSCF, failing to observe any improvement in xylose consumption. Xylose consumption was negligible after $48 \mathrm{~h}$ in our fed-batch SSCF (Fig. 2), although HMF and furfural were promptly converted after each addition of unwashed solids (data not shown), and glucose conversion maintained for at

Table 3 Sugar and end-product concentrations and ethanol and xylitol yields after SSCF

\begin{tabular}{|c|c|c|c|c|c|c|c|c|c|}
\hline & \multirow[t]{3}{*}{ Substrate } & \multicolumn{2}{|c|}{$\begin{array}{l}\text { Solubilized } \\
\text { sugars }\end{array}$} & \multicolumn{2}{|c|}{ End-products } & \multicolumn{3}{|l|}{ Yields } & \multirow{3}{*}{$\begin{array}{l}\text { Xylose utilization } \\
\%\end{array}$} \\
\hline & & \multirow{2}{*}{$\begin{array}{l}\text { Glucose } \\
\mathrm{g} \mathrm{L}^{-1}\end{array}$} & \multirow{2}{*}{$\begin{array}{l}\text { Xylose } \\
\mathrm{g} \mathrm{L}^{-1}\end{array}$} & \multirow{2}{*}{$\begin{array}{l}\text { Xylitol } \\
\mathrm{g} \mathrm{L}^{-1}\end{array}$} & \multirow{2}{*}{$\begin{array}{l}\text { Ethanol } \\
\mathrm{g} \mathrm{L}^{-1}\end{array}$} & \multicolumn{2}{|c|}{ Ethanol $^{\mathrm{a}}$} & \multirow{2}{*}{$\begin{array}{l}\text { Xylitol }^{\mathrm{b}} \\
\%\end{array}$} & \\
\hline & & & & & & $\mathrm{g} \mathrm{g}^{-1}$ & $\%$ & & \\
\hline \multicolumn{10}{|l|}{ Referenced studies } \\
\hline Fed-batch SSCF [30] & STEX-WS & n.r. & n.r. & $\leq 2$ & 38 & 0.35 & 69 & 9 & 49 \\
\hline Fed-batch SSCF [31] & STEX-CC & 0.5 & 16 & 3.4 & 47 & 0.35 & 69 & 11 & 55 \\
\hline Fed-batch SHCF with prefermentation [33] & $\begin{array}{l}\text { STEX-WS } \\
\text { Severe }\end{array}$ & 0.3 & 6.4 & 2.3 & 37 & 0.38 & 75 & 19 & 71 \\
\hline Fed-batch SHCF with prefermentation [33] & $\begin{array}{l}\text { STEX-WS } \\
\text { Mild }\end{array}$ & 0.1 & 0.4 & 1.0 & 41 & 0.42 & 83 & 4 & 97 \\
\hline \multicolumn{10}{|l|}{ This study } \\
\hline $\begin{array}{l}\text { Fed-batch SSCF ("Fed-Batch SSCF of Whole } \\
\text { Slurry" section) }\end{array}$ & $\begin{array}{l}\text { STEX-WS } \\
\text { Severe }\end{array}$ & 7.6 & 8.3 & 2.4 & 28.1 & 0.287 & 56.3 & 14.5 & 66 \\
\hline $\begin{array}{l}\text { Fed-batch SSCF with prefermentation ("Prefermentation } \\
\text { Followed by Fed-Batch SSCF" section) }\end{array}$ & $\begin{array}{l}\text { STEX-WS } \\
\text { Severe }\end{array}$ & 0.0 & 1.5 & 2.9 & 41.9 & 0.428 & 84.0 & 12.6 & 92 \\
\hline $\begin{array}{l}\text { Fed-batch SSCF with prefermentation ("Prefermentation } \\
\text { Followed by Fed-Batch SSCF" section) }\end{array}$ & $\begin{array}{l}\text { STEX-WS } \\
\text { Mild }\end{array}$ & 0.1 & 2.9 & 1.2 & 45.5 & 0.474 & 92.4 & 4.4 & 91 \\
\hline
\end{tabular}

STEX acid-catalyzed steam explosion, $C C$ corn cobs, WS wheat straw, n.r. not reported

${ }^{a}$ Ethanol yield based on total supplied glucose and xylose and related to the maximum theoretical yield $\left(0.51 \mathrm{~g} \mathrm{~g}^{-1}\right)$

${ }^{\mathrm{b}}$ Xylitol yield based on consumed xylose 


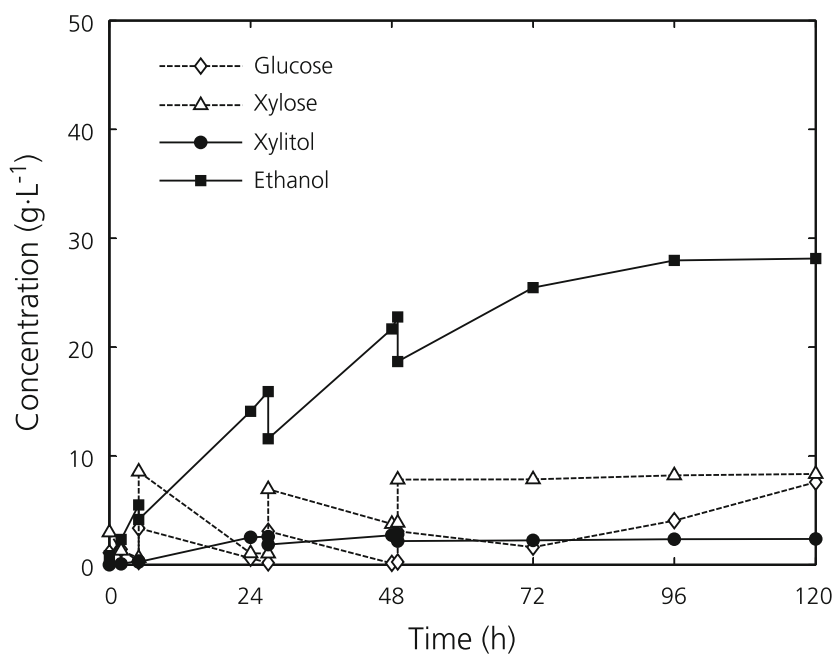

Fig. 2 Time course of fed-batch SSCF of whole severe wheat straw slurry with $2 \mathrm{~h}$ of prefermentation and enzyme feeding. Enzyme additions were made after $2,24,48$, and $72 \mathrm{~h}$, and slurry was added after 5, 27, and $49 \mathrm{~h}$ of co-fermentation

least $96 \mathrm{~h}$, indicating that decrease in xylose-fermenting capacity occurred in part for other reasons, as noted by Olofsson et al. [30].

\section{Fed-Batch SSCF with Prefermentation}

To overcome the limited xylose conversion in the late fermentation phase and improve the overall ethanol yield, we devised a sequential fermentation strategy, comprising batch prefermentation of the xylose-rich hydrolyzate liquor followed by fed-batch SSCF (Fig. 1b). The crude separation between xylose-rich hydrolyzate liquor and glucose-rich lignocellulosic solids enabled us to develop a fermentation strategy in which conversion of xylose and glucose could be targeted sequentially.

\section{Fed-Batch SSCF with Prefermentation of Severe Hydrolyzate Liquor}

The results of the co-fermentation of severe wheat straw slurry with the proposed strategy are shown in Fig. 3. The overall ethanol yield was improved by $49 \%$ compared with fed-batch SSCF of whole slurry, which was attributed to the sustained xylose-fermenting capacity and, thus, greater xylose utilization (Table 3).

The batch prefermentation of xylose-rich severe hydrolyzate liquor depleted glucose and consumed $73 \%$ of the xylose in the hydrolyzate liquor, equaling $45 \%$ of the total available xylose in the hydrolyzate liquor and WIS. The metabolic ethanol yield after prefermentation was $63.9 \%$ of the theoretical maximum, and $12.5 \%$ of the consumed xylose was converted to xylitol. Further, the severe hydrolyzate liquor was detoxified in situ during prefermentation, thus, relieving the

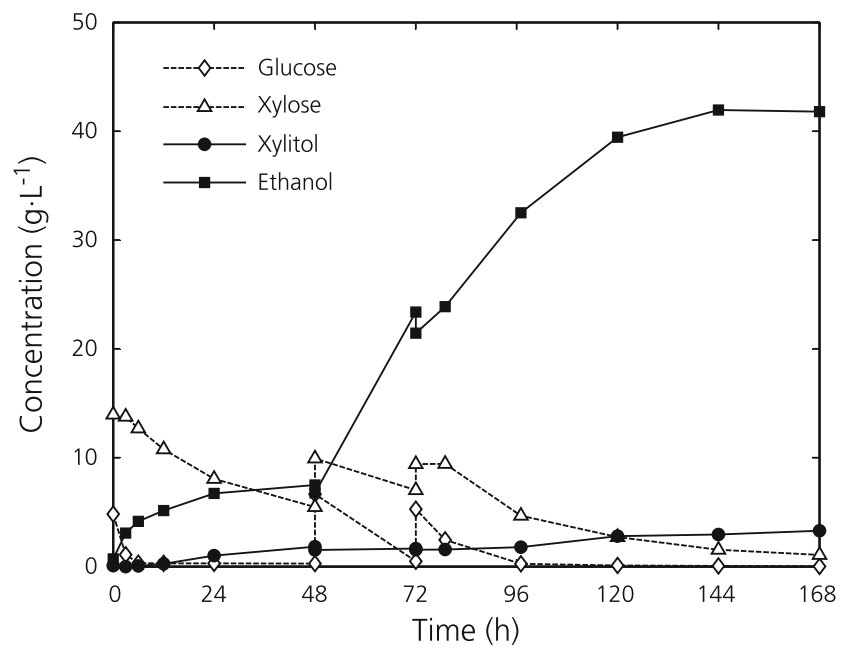

Fig. 3 Time course of SSCF with 48-h batch prefermentation of severe hydrolyzate liquor and fed-batch addition of unwashed severe solids

inhibitory burden on the pitched yeast during fed-batch SSCF. In addition, the lower temperature during prefermentation- 30 versus $35^{\circ} \mathrm{C}$ during SSCF-likely helped to sustain the viability of $S$. cerevisiae during fermentation, as shown by Torija et al. [44].

The subsequent fed-batch SSCF resulted in an ethanol concentration of $41.9 \mathrm{~g} \mathrm{~L}^{-1}$ after $144 \mathrm{~h}$, which corresponded to an overall ethanol yield of $84 \%$ of the theoretical maximum (Table 3). Solubilized glucose was depleted, and the xylose concentration in the broth after fermentation was $1.5 \mathrm{~g} \mathrm{~L}^{-1}$. Xylose utilization reached $92 \%$ of the total available xylose, and $12.6 \%$ of consumed xylose was converted to xylitol (Table 3). No further gains in ethanol titers or yield were obtained with prolonged fermentation after $144 \mathrm{~h}$ (Fig. 3), although xylose consumption was sustained. The xylose conversion after $144 \mathrm{~h}$ and on was primarily coupled to xylitol production. Approximately $40 \%$ of all xylitol was produced after the 96-h point in the fed-batch SSCF. This change coincided with the depletion of measured glucose (Fig. 3) and furfural in the fermentation broth (data not shown). The increase in xylitol production was likely due to predominantly xylose being consumed and a co-factor imbalance in the XR/ XDH pathway [19].

Prefermentation of the xylose-rich hydrolyzate liquor under advantageous conditions converted a significant fraction of the total available xylose. Subsequently, the glucan was hydrolyzed enzymatically to glucose and converted during the fed-batch SSCF, and most of the remaining xylose was co-consumed. Because the fermenting microorganism loses its xylose-fermenting capacity over time [30] but still converts glucose to ethanol, it was advantageous for the overall xylose utilization to target xylose conversion first and subsequently glucose conversion. The concept of sequential targeting of xylose and glucose conversion has been demonstrated by Jin et al. [32]. They showed that xylose consumption and ethanol 
yield was improved with 2-step batch SSCF of AFEXpretreated switchgrass with independent xylanase and cellulase feeding.

Xylose utilization was further promoted by the low glucose concentrations in the fermentation broth throughout the fedbatch SSCF (Fig. 3). In our sequential co-fermentation strategy, we used a simpler feeding scheme than for fed-batch SSCF of whole slurry. Whereas fed-batch SSCF of whole slurry used several additions of substrate and enzymes to maintain low glucose concentrations, the entire enzyme load was added prior to the fed-batch SSCF phase in our strategy - to prevent the hydrolysis rate from limiting ethanol production and yield - and only two additions of unwashed solids were performed. The feed of unwashed solids during fed-batch SSCF was used to restrict the hydrolytic release of glucose in the bioreactor. The number of additions of unwashed solids that we made during fed-batch SSCF was a tradeoff between capping the glucose concentration in the fermentation broth and preventing exhaustion of the microorganism. This tradeoff exists, because continuous feeding and repeat addition of substrate that contains inhibitors adversely affect the viability of S. cerevisiae KE6-12 [33]. Similarly, the choice of batch prefermentation of the hydrolyzate liquor was a tradeoff between conserving viability and minimizing xylitol production, because fed-batch prefermentation results in lower overall xylitol yields than batch prefermentation but is detrimental to the viability of the fermenting microorganism [33].

\section{Fed-Batch SSCF with Prefermentation of Mild Hydrolyzate Liquor}

Prefermentation and fed-batch SSCF of hydrolyzate liquor and unwashed solids from mild wheat straw slurry (Fig. 4) were performed to determine the performance at lower inhibitor concentrations. The overall ethanol yield after

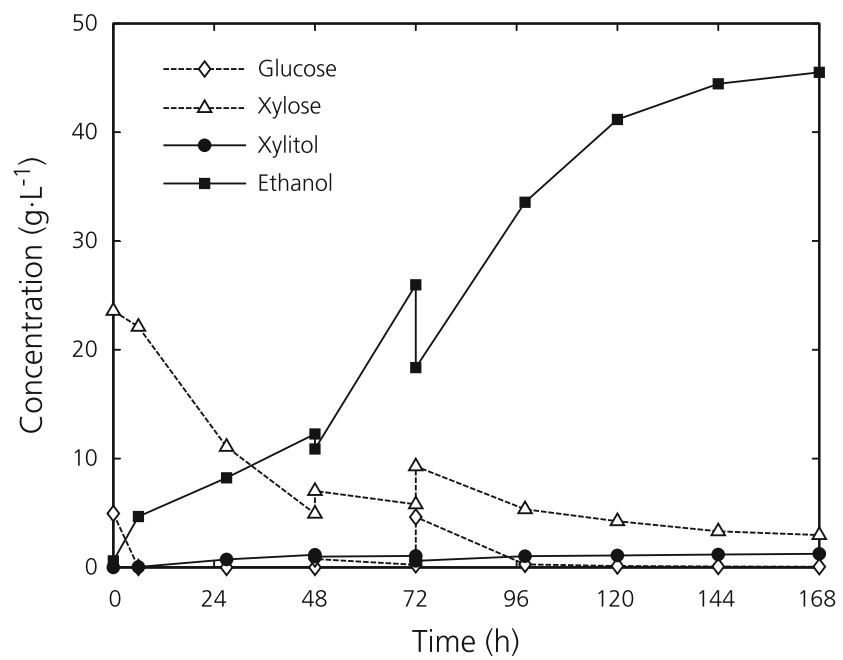

Fig. 4 Time course of SSCF with 48-h batch prefermentation of mild hydrolyzate liquor and fed-batch addition of unwashed mild solids prefermentation and fed-batch SSCF with mild slurry improved significantly compared with co-fermentation of severe slurry with the same strategy.

The batch prefermentation of mild hydrolyzate liquor resulted in the depletion of glucose and the consumption of $83 \mathrm{wt} \%$ of the available xylose in the hydrolyzate liquor, of which $4.8 \mathrm{wt} \%$ was converted to xylitol. The xylose that was consumed during prefermentation was equal to $62 \mathrm{wt} \%$ of total available xylose. The increase in xylose utilization and lower xylitol production reflected improvements compared to prefermentation of severe hydrolyzate liquor. A metabolic ethanol yield of $78.6 \%$ of the theoretical maximum was obtained after prefermentation.

The subsequent fed-batch SSCF resulted in an ethanol concentration of $45.5 \mathrm{~g} \mathrm{~L}^{-1}$ after $168 \mathrm{~h}$ of co-fermentation, which corresponded to an overall ethanol yield of $92.4 \%$ of the theoretical maximum yield (Table 3). Solubilized glucose was depleted, and the xylose concentration in the fermentation broth after fermentation was $2.9 \mathrm{~g} \mathrm{~L}^{-1}$. Xylose utilization reached $91 \mathrm{wt} \%$ of the total ingoing xylose, of which $4.4 \mathrm{wt} \%$ of consumed xylose was converted to xylitol (Table 3). Furaldehydes were promptly converted to their less toxic reduced form after each addition of substrate (data not shown), and the ethanolic co-fermentation of glucose and xylose was sustained throughout the $168 \mathrm{~h}$ of co-fermentation. The lower xylitol production compared with severe slurry was in part caused by lower xylose consumption in the late SSCF fermentation phase. The ethanol production after $144 \mathrm{~h}$ and on with mild slurry was based largely on the hydrolytic release of monosaccharides from lignocellulosic solids (Fig. 4), in contrast to severe slurry, for which primarily solubilized xylose was consumed and converted to xylitol (Fig. 3).

The lower WIS content of the mild slurry-11.1 wt $\%$ compared with $13.9 \mathrm{wt} \%$ WIS in the severe slurry-required a lower dilution to obtain a WIS load of $10 \mathrm{wt} \%$ in the cofermentation. As a result, higher sugar concentrations were obtained during prefermentation with mild hydrolysate. Despite the greater dilution of the severe hydrolysate liquor, inhibitor concentrations remained higher than with mild hydrolysate liquor. However, the differences in ethanol yield cannot be explained solely by the differences in inhibitor concentration. Alternatively, the higher xylose-to-glucose ratio of the mild hydrolysate liquor seemed to have a positive impact on ethanol production. The effect of lower inhibitor concentration in the original mild slurry was more pronounced during the fed-batch SSCF step, in which considerably lower inhibitor concentrations were observed. Inhibitors were added to the fermentation broth with each addition of unwashed solids, because a fraction of the hydrolysate liquor remained with the solids after filtration.

The overall ethanol yield improved significantly with mild slurry, which was attributed to weaker inhibitory effects and lower xylitol production (Table 3). The difference in co- 
fermentation outcomes between mild and severe wheat straw slurry confirmed the importance of pretreatment methods that disrupt the inherent recalcitrance of lignocellulosic material and simultaneously generate low concentrations of inhibitory degradation products. Keeping inhibitor concentrations low, while maintaining hydrolyzability, is paramount for improving ethanol yields.

\section{Comparison with Previous SSCF Studies}

Regardless of fermenting microorganism, pretreatment, and raw material, the fermentation behavior in fed-batch SSCF of whole slurry was similar-xylose consumption declined over time. The inhibitor concentrations in mild and severe slurry were comparable with those in fed-batch SSCF in Olofsson et al. [30] and Koppram et al. [31], respectively (Table 2). Taking these results into consideration, the sequential targeting of xylose and glucose conversion with prefermentation of hydrolyzate liquor followed by fed-batch SSCF improved the process compared with fed-batch SSCF of whole slurry. With our strategy, the xylose-fermenting capacity was sustained throughout the co-fermentation, regardless of inhibitor concentrations in the slurries. Xylose utilizations that exceeded $90 \%$ of the total available xylose were obtained with both slurries, improving the xylose utilization with $\geq 65 \%$ compared to the referenced studies (Table 3 ).

Olofsson et al. [30] applied a considerably shorter fermentation time, $100 \mathrm{~h}$, but xylose consumption after $40 \mathrm{~h}$ and on was limited. Koppram et al. [31] used a similar fermentation time as in our study but observed much lower xylose consumption than with prefermentation followed by fed-batch SSCF (Table 3). The improved xylose utilization with prefermentation of the separated hydrolyzate liquor followed by fed-batch SCCF with unwashed solids, thus, contributed significantly to the improved the overall ethanol yield. The overall ethanol yields were improved by $>20 \%$ compared to the referenced studies (Table 3).

\section{SSCF versus SHCF}

To evaluate SSCF that is coupled to prefermentation versus SHCF, the outcomes were compared to those of Nielsen et al. [33], which examined the same pretreated raw material and fermenting microorganism (Table 2). With prefermentation of the hydrolyzate liquor followed by fed-batch SSCF or SHCF, the xylose-fermenting capacity was sustained throughout the co-fermentation, thus, effecting high xylose utilization. However, the ethanol concentrations and overall ethanol yields that were obtained with fed-batch SSCF of mild and severe slurry exceeded those obtained with SHCF that was coupled to prefermentation [33]. The SHCF strategy elicited overall ethanol yields of 83 and $75 \%$ of the theoretical maximum, respectively, for co-fermentation of mild and severe slurry, whereas the SSCF strategy resulted in overall ethanol yields of 92 and $84 \%$, respectively (Table 3). The improvement in ethanol yields reinforced the notion that SSF typically results in higher yields than SHF [25, 26].

Further, the suboptimal conditions for hydrolysis that are needed to accommodate simultaneous saccharification and fermentation imply the risk of rendering the hydrolysis ratelimiting for ethanol production. Prefermentation followed by fed-batch SSCF had longer fermentation times before stagnation of ethanol formation, indicating that hydrolysis was ratelimiting for ethanol production. Prefermentation followed by fed-batch SSCF with mild slurry also resulted in higher xylose concentrations in the broth after fermentation than prefermentation followed by SHCF [33], which resulted in lower xylose utilization. This trend was also observed for SSCF and SHCF without prefermentation by Olsson et al. [26].

\section{Process Considerations}

With regard to process and economic perspectives, there are several aspects to consider. With high ethanol yields, final ethanol concentrations for cost-efficient downstream processing can be reached with relatively low WIS loads. In this study, we obtained ethanol concentrations above $40 \mathrm{~g} \mathrm{~L}^{-1}$, which is generally regarded as the lower limit for costeffective recovery of ethanol [45, 46], with a WIS load of $10 \mathrm{wt} \%$. The improved xylose utilization and overall ethanol yield are also expected to benefit the overall process economics $[3,4]$. Further, the fractionation of slurry was linked to the possibility of targeting xylose and glucose conversion in succession and concurrently maintaining low viscosity in the bioreactor by fed-batch SSCF, in which the viscosity decreases continuously by enzymatic degradation. Keeping the viscosity low ensures proper mixing, which becomes increasingly important, as the WIS loads are increased above the applied $10 \mathrm{wt} \%$ WIS. Furthermore, prefermentation prolongs the fermentation time and consequently negatively affects ethanol productivity for a given fermentor capacity. Thus, there is a tradeoff between ethanol yield and productivity with this method.

\section{Conclusions}

Our SSCF strategy sustained xylose fermentation throughout fermentation, and prefermentation of hydrolyzate liquor followed by fed-batch SSCF improved xylose utilization and ethanol yield compared with fed-batch SSCF with enzyme feeding. With our strategy, an overall ethanol yield of $84 \%$ of the theoretical maximum was reached at higher inhibitor concentrations in the slurry, versus $92 \%$ at lower inhibitor concentrations. Xylose utilization exceeded $90 \%$ after SSCF 
for both slurries. The suggested SSCF strategy resulted in overall ethanol yields that superseded those in corresponding SHCF strategies, thus, reinforcing the notion that SSCF in general attains higher yields.

DM, dry matter; FPU, filter paper unit; HMF, 5hydroxymethylfurfural; HPLC, high-performance liquid chromatography; SHCF, separate hydrolysis and co-fermentation; SSCF, simultaneous saccharification and co-fermentation; vvm, gas volume flow per unit of liquid volume per minute; WIS, water-insoluble solids; XDH, xylitol dehydrogenase; $\mathrm{XI}$, xylose isomerase; XK, xylulokinase; XR, xylose reductase.

Acknowledgements The Swedish Energy Agency is gratefully acknowledged for their financial support (process development for combined pentose and hexose fermentation, 35354-1), as is Taurus Energy $\mathrm{AB}$ for co-financing the project.

Authors' Contributions FN participated in the conception and design of the study, performed the experiments, and wrote the manuscript. GZ participated in the conception and design of the study and critically reviewed the manuscript. OW and MG assisted in interpreting the data, participated in the editing and preparation of the final manuscript, and critically reviewed the manuscript. All authors read and approved the final manuscript.

\section{Compliance with Ethical Standards}

Availability of Data and Materials The datasets supporting the conclusions of this article are included within the article.

Competing Interests The study was part of the project "Process development for combined pentose and hexose fermentation", which was cofinanced by Taurus Energy AB. GZ is a shareholder and a member of the board at Taurus Energy AB. The remaining authors declare no financial competing interests, and all authors declare that they have no nonfinancial competing interests.

Funding The study was performed as a part of the project Process development for combined pentose and hexose fermentation funded by The Swedish Energy Agency (Grant number, 35354-1) and co-financed by Taurus Energy AB.

Open Access This article is distributed under the terms of the Creative Commons Attribution 4.0 International License (http:// creativecommons.org/licenses/by/4.0/), which permits unrestricted use, distribution, and reproduction in any medium, provided you give appropriate credit to the original author(s) and the source, provide a link to the Creative Commons license, and indicate if changes were made.

\section{References}

1. Chovau S, Degrauwe D, van der Bruggen B (2013) Critical analysis of techno-economic estimates for the production cost of lignocellulosic bio-ethanol. Renew Sust Energ Rev 26:307-321

2. von Sivers M, Zacchi G (1996) Ethanol from lignocellulosics: a review of the economy. Bioresour Technol 56:131-140
3. Joelsson E, Dienes D, Kovacs K et al (2016) Combined production of biogas and ethanol at high solids loading from wheat straw impregnated with acetic acid: experimental study and technoeconomic evaluation. Sustain Chem Process 4(1):1-19

4. Gnansounou E, Dauriat A (2010) Techno-economic analysis of lignocellulosic ethanol: a review. Bioresour Technol 101(13): 4980-4991

5. Hahn-Hägerdal B, Karhumaa K, Fonseca C et al (2007) Towards industrial pentose-fermenting yeast strains. Appl Microbiol Biotechnol 74(5):937-953

6. Eliasson A, Christensson C, Wahlbom CF et al (2000) Anaerobic xylose fermentation by recombinant Saccharomyces cerevisiae carrying XYL1, XYL2, and XKS1 in mineral medium chemostat cultures. Appl Environ Microbiol 66(8):3381-3386

7. Kötter P, Amore R, Hollenberg CP et al (1990) Isolation and characterization of the Pichia stipitis xylitol dehydrogenase gene, XYL2, and construction of a xylose-utilizing Saccharomyces cerevisiae transformant. Curr Genet 18(6):493-500

8. van Maris AJ, Winkler AA, Kuyper M et al (2007) Development of efficient xylose fermentation in Saccharomyces cerevisiae: xylose isomerase as a key component. Adv Biochem Eng Biotechnol 108: 179-204

9. Toivari MH, Aristidou A, Ruohonen L et al (2001) Conversion of xylose to ethanol by recombinant Saccharomyces cerevisiae: importance of xylulokinase (XKS1) and oxygen availability. Metab Eng 3(3):236-249

10. Watanabe S, Abu Saleh A, Pack SP et al (2007) Ethanol production from xylose by recombinant Saccharomyces cerevisiae expressing protein-engineered NADH-preferring xylose reductase from Pichia stipitis. Microbiology 153(9):3044-3054

11. Petschacher B, Nidetzky B (2008) Altering the coenzyme preference of xylose reductase to favor utilization of NADH enhances ethanol yield from xylose in a metabolically engineered strain of Saccharomyces cerevisiae. Microb Cell Factories 7:9

12. Wisselink HW, Toirkens MJ, Wu Q et al (2009) Novel evolutionary engineering approach for accelerated utilization of glucose, xylose, and arabinose mixtures by engineered Saccharomyces cerevisiae strains. Appl Environ Microbiol 75(4):907-914

13. Almeida JRM, Modig T, Petersson A et al (2007) Increased tolerance and conversion of inhibitors in lignocellulosic hydrolysates by Saccharomyces cerevisiae. J Chem Technol Biotechnol 82(4):340 349

14. Nielsen F, Tomás-Pejó E, Olsson L et al (2015) Short-term adaptation during propagation improves the performance of xylosefermenting Saccharomyces cerevisiae in simultaneous saccharification and co-fermentation. Biotechnol Biofuels 8(1):1-15

15. Matsushika A, Inoue H, Kodaki T et al (2009) Ethanol production from xylose in engineered Saccharomyces cerevisiae strains: current state and perspectives. Appl Microbiol Biotechnol 84(1):37-53

16. Sonderegger M, Jeppsson M, Larsson C et al (2004) Fermentation performance of engineered and evolved xylose-fermenting Saccharomyces cerevisiae strains. Biotechnol Bioeng 87(1):90-98

17. Kötter P, Ciriacy M (1993) Xylose fermentation by Saccharomyces cerevisiae. Appl Microbiol Biotechnol 38(6):776-783

18. Bruinenberg PM, de Bot PH, van Dijken JP et al (1983) The role of redox balances in the anaerobic fermentation of xylose by yeasts. Eur J Appl Microbiol Biotechnol 18(5):287-292

19. Verho R, Londesborough J, Penttilä M et al (2003) Engineering redox cofactor regeneration for improved pentose fermentation in Saccharomyces cerevisiae. Appl Environ Microbiol 69(10):58925897

20. Hamacher T, Becker J, Gardonyi M et al (2002) Characterization of the xylose-transporting properties of yeast hexose transporters and their influence on xylose utilization. Microbiology-Sgm 148:27832788 
21. Meinander NQ, Boels I, Hahn-Hägerdal B (1999) Fermentation of xylose/glucose mixtures by metabolically engineered Saccharomyces cerevisiae strains expressing XYL1 and XYL2 from Pichia stipitis with and without overexpression of TAL1. Bioresour Technol 68(1):79-87

22. Pitkänen J-P, Aristidou A, Salusjärvi L et al (2003) Metabolic flux analysis of xylose metabolism in recombinant Saccharomyces cerevisiae using continuous culture. Metab Eng 5(1):16-31

23. Boles E, Müller S, Zimmermann FK (1996) A multi-layered sensory system controls yeast glycolytic gene expression. Mol Microbiol 19(3):641-642

24. Alfani F, Gallifuoco A, Saporosi A et al (2000) Comparison of SHF and SSF processes for the bioconversion of steam-exploded wheat straw. J Ind Microbiol Biotechnol 25(4):184-192

25. Tomás-Pejó E, Oliva JM, Ballesteros M et al (2008) Comparison of SHF and SSF processes from steam-exploded wheat straw for ethanol production by xylose-fermenting and robust glucosefermenting Saccharomyces cerevisiae strains. Biotechnol Bioeng 100(6):1122-1131

26. Olsson L, Soerensen HR, Dam BP et al (2006) Separate and simultaneous enzymatic hydrolysis and fermentation of wheat hemicellulose with recombinant xylose utilizing Saccharomyces cerevisiae. Appl Biochem Biotechnol 129(1-3):117-129

27. Olofsson K, Rudolf A, Lidén G (2008) Designing simultaneous saccharification and fermentation for improved xylose conversion by a recombinant strain of Saccharomyces cerevisiae. J Biotechnol 134(1-2):112-120.

28. Olofsson K, Wiman M, Lidén G (2010) Controlled feeding of cellulases improves conversion of xylose in simultaneous saccharification and co-fermentation for bioethanol production. J Biotechnol 145(2):168-175

29. Bertilsson M, Olofsson K, Lidén G (2009) Prefermentation improves xylose utilization in simultaneous saccharification and cofermentation of pretreated spruce. Biotechnol Biofuels 2(8)

30. Olofsson K, Palmqvist B, Lidén G (2010) Improving simultaneous saccharification and co-fermentation of pretreated wheat straw using both enzyme and substrate feeding. Biotechnol Biofuels 3: $17-17$

31. Koppram R, Nielsen F, Albers E et al (2013) Simultaneous saccharification and co-fermentation for bioethanol production using corncobs at lab, PDU and demo scales. Biotechnol Biofuels 6(2)

32. Jin M, Lau MW, Balan V et al (2010) Two-step SSCF to convert AFEX-treated switchgrass to ethanol using commercial enzymes and Saccharomyces cerevisiae 424A(LNH-ST). Bioresour Technol 101(21):8171-8178

33. Nielsen F, Zacchi G, Galbe M et al (2016) Prefermentation improves ethanol yield in separate hydrolysis and cofermentation of steam-pretreated wheat straw. Sustain Chem Process 4(1):1-12
34. Albers E, Halpin R, Olsson L (2016) Evolutionary engineering for development of improved xylose utilization capacity and inhibitor tolerance in an industrial Saccharomyces cerevisiae strain. (Manuscript in preparation).

35. Wahlbom CF, van Zyl WH, Jönsson LJ et al (2003) Generation of the improved recombinant xylose-utilizing Saccharomyces cerevisiae TMB 3400 by random mutagenesis and physiological comparison with Pichia stipitis CBS 6054. FEMS Yeast Res 3(3): 319-326

36. Taherzadeh MJ, Lidén G, Gustafsson L et al (1996) The effects of pantothenate deficiency and acetate addition on anaerobic batch fermentation of glucose by Saccharomyces cerevisiae. Appl Microbiol Biotechnol 46(2):176-182

37. Sluiter A, Hames B, Hyman D, et al. (2008) Determination of total solids in biomass and total dissolved solids in liquid process samples Laboratory analytical procedure (LAP). NREL/TP 510-42621. National Renewable Energy Laboratory: Golden.

38. Sluiter A, Hyman D, Payne C, et al. (2008) Determination of insoluble solids in pretreated biomass material Laboratory analytical procedure (LAP). NREL/TP 510-42627. National Renewable Energy Laboratory: Golden.

39. Sluiter A, Hames B, Ruiz R, et al. (2008) Determination of sugars, byproducts, and degradation products in liquid fraction process samples Laboratory analytical procedure (LAP). NREL/TP 51052623. National Renewable Energy Laboratory: Golden.

40. Sluiter A, Hames B, Ruiz R, et al. (2010) Determination of structural carbohydrates and lignin in biomass Laboratory analytical procedure (LAP). NREL/TP 510-42618. National Renewable Energy Laboratory: Golden.

41. Palmqvist B, Lidén G (2014) Combining the effects of process design and $\mathrm{pH}$ for improved xylose conversion in high solid ethanol production from Arundo donax. AMB Express 4(1):41

42. Grohmann K (1993) Simultaneous saccharification and fermentation of cellulosic substrates to ethanol. In: Saddler JN (ed) Bioconversion of forest and agricultural plant residues. $\mathrm{CAB}$ International, Wallingford, pp 183-183

43. Aldiguier AS, Alfenore S, Cameleyre X et al (2004) Synergistic temperature and ethanol effect on Saccharomyces cerevisiae dynamic behaviour in ethanol bio-fuel production. Bioprocess Biosyst Eng 26(4):217-222

44. Torija MJ, Rozès N, Poblet M et al (2003) Effects of fermentation temperature on the strain population of Saccharomyces cerevisiae. Int J Food Microbiol 80(1):47-53

45. Viikari L, Vehmaanperä J, Koivula A (2012) Lignocellulosic ethanol: from science to industry. Biomass Bioenergy 46:13-24

46. Galbe M, Sassner P, Wingren A et al (2007) Process engineering economics of bioethanol production. Adv Biochem Eng Biotechnol 108:303-327 